\title{
Established and experimental medical therapy of pulmonary sarcoidosis
}

\author{
Robert P. Baughman*, Hilario Nunes", Nadera J. Sweiss" and Elyse E. Lower*,+
}

\begin{abstract}
The treatment options for pulmonary sarcoidosis have increased over the past 10 years. As new treatments have been introduced, the best way to assess and compare treatments remains unknown. The goal of this review is to discuss the standard treatments for pulmonary sarcoidosis, including glucocorticoids, and cytotoxic agents, such as methotrexate, azathioprine and leflunomide, and compare them to the newer biological agents, such as infliximab and adalimumab. We also discuss some novel treatments which are currently being evaluated. To compare these different regimens, we look at the measures used to assess response. These include pulmonary function, chest imaging, steroid sparing potential and, more recently, improvements in quality of life measures. While there is, as yet, no standard assessment for response, there is a growing consensus that response to treatment may include improvement of one or more of the following: forced vital capacity, chest imaging and steroid sparing. Several drugs used for pulmonary sarcoidosis have demonstrated improvement in one or more of these measures.
\end{abstract}

$\mathbf{T}$ he treatment of pulmonary sarcoidosis remains mostly empiric. Based on current literature, evidence based recommendations have been made [1, 2]. However, the recommendations are mostly level two or three, based on a limited number of double-blind placebo-controlled trials $[3,4]$. In particular, there have been no high quality placebo-controlled double-blind studies of the classical drugs used to treat sarcoidosis, such as glucocorticoids. One of the difficulties in the current literature has been the lack of standard criteria for treatment indications for therapy and standardised validated follow-up measures to determine response to therapy [5]. Approach to treatment of pulmonary sarcoidosis is challenging for the treating physician, as well as for the researcher, given the multisystem nature of the disease and the lack of validated phenotype specific measures. Despite these limitations, an increasing number of drugs have been studied for pulmonary sarcoidosis.

The indications for corticosteroid and/or corticosteroid sparing therapy have included improving lung function, prevention of worsening of pulmonary disease, and steroid sparing. Table 1 summarises the most common outcome measurements used. These include pulmonary function testing, chest imaging, quality of life instruments, and steroid sparing. In some studies a combination of factors are used to assess response [14, 15]; however, these are not standardised. In this review, we will address the various standard, as well as new, treatments for sarcoidosis. We will then discuss the effectiveness of various agents, old and new.

\section{ASSESSING RESPONSE TO THERAPY}

Pulmonary function

The forced vital capacity (FVC) has been the most widely used parameter to measure response to treatment for pulmonary sarcoidosis. There are several methods to assess response, but the two most widely reported are changes in the per cent predicted and the absolute change in litres. Table 2 summarises some of the studies using various agents to treat pulmonary sarcoidosis. In some cases, there was a placebo group. Comparisons can be made to baseline studies or between groups. In one study, the authors were able to analyse the change in FVC prior to the institution of their intervention and compare that to 6 months after starting leflunomide [25]. This design nicely

Previous articles in this series: No. 1: Schlobin OA, Nathan SD. Management of end-stage sarcoidosis: pulmonary hypertension and lung transplantation. Eur Respir J 2012; 39: 1521-1534. No. 2: Drent M, Lower EE, De Vries J. Sarcoidosis-associated fatigue. Eur Respir J 2012; 40: 255-263. No. 3: Nunes H, Uzunhan Y, Gille T, et al. Imaging of sarcoidosis of the airways and lung parenchyma and correlation with lung function. Eur Respir J 2012; 40: 750-765. No. 4: Keijsers RGM, van den Heuvel DAF, Grutters JC. Imaging the inflammatory activity of sarcoidosis. Eur Respir J 2013; 41: 743-751.

AFFILIATIONS

*Dept of Medicine, University of Cincinnati Medical Center, Cincinnati, $\mathrm{OH}$

'Dept of Medicine, University of Illinois, Chicago, IL, and ${ }^{+}$Oncology Hematology Care, Cincinnati, OH, USA. \# Service de Pneumologie, Hôpital Avicenne, Assistance Publique Hôpitaux de Paris, EA2363 Université Paris 13, Bobigny, France.

CORRESPONDENCE

R.P. Baughman

Interstitial Lung Disease and Sarcoidosis clinic, Dept of Medicine University of Cincinnati

Cincinnati

OH 45267

USA

E-mail: bob.baughman@uc.edu

Received:

April 112012

Accepted after revision:

Jan 192013

First published online:

Feb 082013

European Respiratory Journa

Print ISSN 0903-1936

Online ISSN 1399-3003 
demonstrated that the patients they were studying were getting worse prior to the intervention and had a significant response after intervention.

The reported level of improvement of FVC with corticosteroid therapy varies widely. In retrospective reviews, up to $14 \%$ absolute improvement in the FVC has been noted [31]. However, in placebo controlled trials, it is not clear that the response is greater than that seen with placebo [3]. As demonstrated in table 2, the treatment schedule and duration of follow-up leads to differences in response to corticosteroids [14, 16, 17]. In some studies, an initial improvement was not maintained [32].

The type of patients studied also affects the response to treatment. Patients who have been treated with corticosteroids are often treated with other agents, either to minimise corticosteroid toxicity or due to a lack of efficacy in refractory patients [33]. Further improvement in FVC may be small. In a double-blind, placebo-controlled trial of infliximab for chronic pulmonary disease, there was a small, but significant improvement in FVC for those who received infliximab. However, the degree of response was greater for those with more severe disease, i.e. those with lower FVC [28]. In a post hoc analysis of this study, it was found that those patients with an elevated Creactive protein (CRP) had a doubling of the improvement in the FVC compared to placebo [29]. Other biomarkers may be useful to identify which patients will respond to therapy [34].

In table 2, we demonstrate the change in FVC per cent predicted and the absolute volume of change. Absolute changes in FVC per cent predicted are useful to compare studies. This value has been used for other interstitial lung diseases such as idiopathic pulmonary fibrosis, where a decline of $5 \%$ or greater is associated with an increased mortality [35]. It has also been demonstrated that changes of FVC from 2-6\% represent the minimal clinically important difference [19]. In sarcoidosis, it is not clear which is the best way to follow changes in FVC [5].

In addition to the mean change in FVC, the number of patients with improvement of FVC by $10-15 \%$ has also been felt to be a clinically important measure. While such large changes can be seen in the treatment of asthma, these large changes were not seen in recent positive placebo-controlled trials of restrictive lung diseases, such as idiopathic pulmonary fibrosis [36] and scleroderma associated pulmonary fibrosis [37]. For sarcoidosis, only a limited number of studies have reported the frequency that this occurs with therapy $[15,28,38]$. Usually less than half of patients demonstrate such a response and in some cases, no patients have such a large improvement.

The forced expiratory volume in $1 \mathrm{~s}$ (FEV1) is a measure commonly reported with the FVC. Sarcoidosis can cause obstructive disease in a significant number of patients [39], so changes in FEV1 may provide additional information over the FVC. Improvement in FEV1 without changes in FVC can be seen in some cases when airway obstruction is the major manifestation of the disease [40]. Airway stenosis may be unresponsive to antiinflammatory therapy, especially if not treated within the first 6 months of onset of airflow limitation [41].

The transfer of carbon monoxide (DLCO or TLCO) has also been reported in a limited number of studies. There was a significant improvement, compared placebo treated patients, in some corticosteroid studies [16, 42] while not in others [14]. The advantage of this measure is that it is more sensitive to interstitial lung disease [5]. However, the test is more difficult to reproduce and has been used less frequently in large clinical trials. In addition, other factors such as pulmonary hypertension may lead to reduction of the DLCO [43]. Since pulmonary hypertension is often unresponsive to anti-inflammatory

\section{TABLE 1 Measurements in pulmonary sarcoidosis}

Instrument

Comments

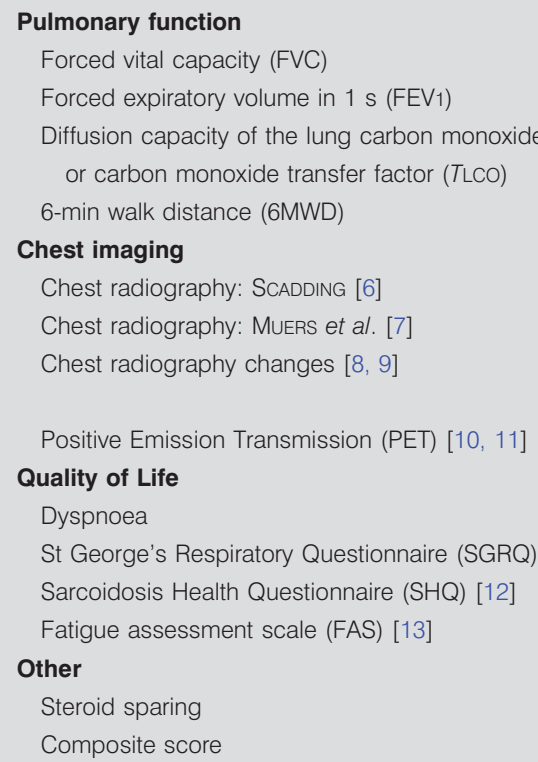

Most commonly used measure of response to therapy

Commonly reported but not clear what additional information it adds to FVC Not as widely used as FVC, more difficult to perform standardly across centres

More recent test, changes are due to multiple factors

Standard scoring system, five point scale Standardised measurement of changes in chest radiography, not used clinically Comparison of radiographs prior to and after intervention, best done in a blinded and random order

Several instruments available

Quality of life instrument, not specific for sarcoidosis

Sarcoidosis specific quality of life instrument

Standard scoring system, fifty point scale

Most studies do not specify the steroid tapering schedule

No standard system 


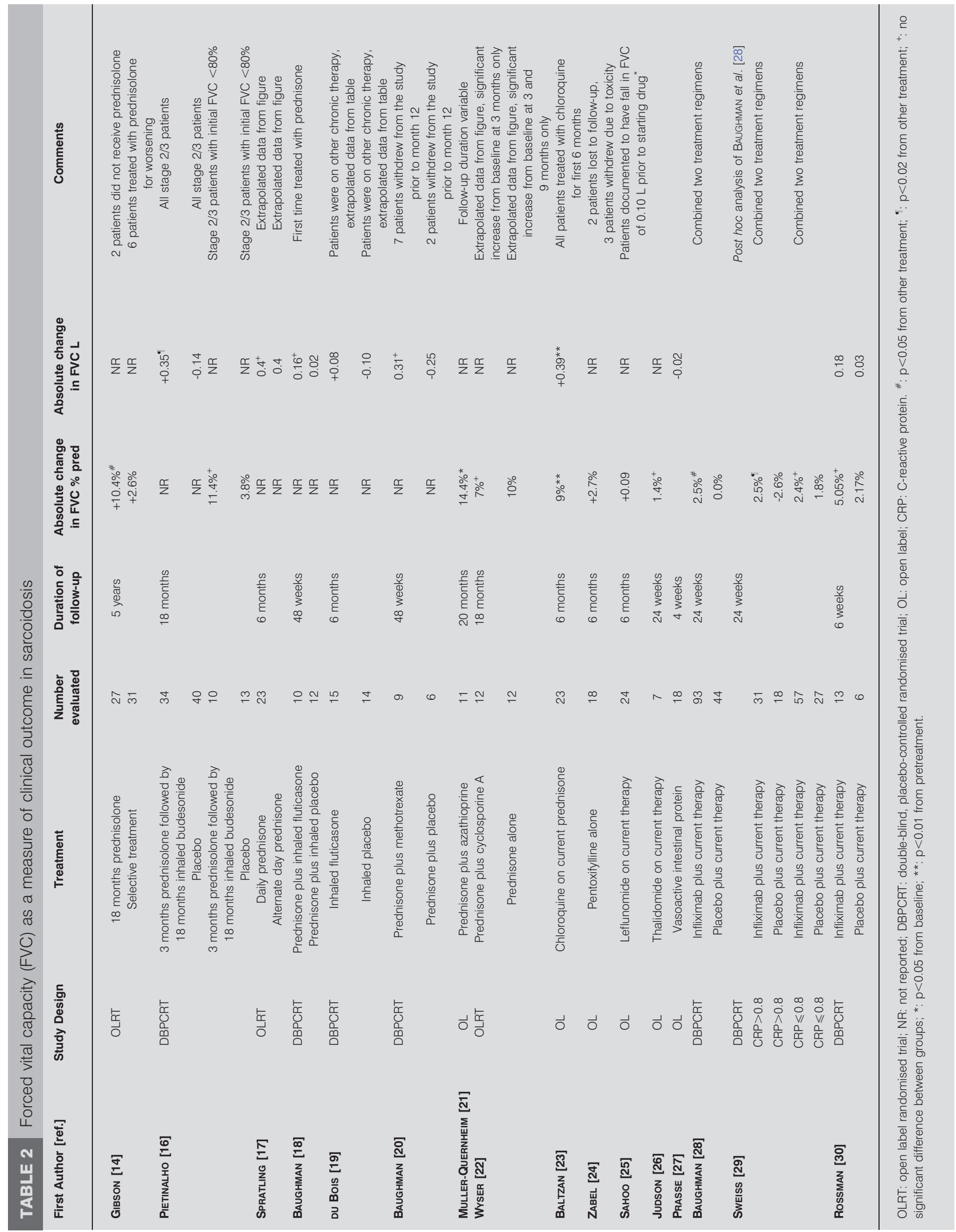


therapy [44], the DLCO may remain unchanged while there could be significant improvements in FVC and other parameters.

The 6-min walk distance (6MWD) is a simple measure of the cardiopulmonary status of sarcoidosis patients [45]. For interstitial lung disease, the test has been shown to be quite reproducible [46]. However, several factors can influence the 6MWD [47]. Improvement in 6MWD has been found with some patients after therapy [29]. However, changes in 6MWD were not demonstrated in other intervention studies [48-50].

\section{Chest imaging}

A traditional method of characterising lung involvement in sarcoidosis is the staging system originally reported by SCADDING [6]. For many years, there has been controversy about applying this staging system to response to therapy [51]. One of the difficulties has been the reproducibility of the staging system [8]. Another factor is the poor correlation between chest radiograph stage and other pulmonary parameters, such as FVC and dyspnoea [52]. It is not clear that a change of chest radiograph stage from three to two is actually an improvement in the patient's condition, or simply a difference in opinion about whether the patient has mediastinal and hilar adenopathy (stage 2) or not (stage 3).

MuERs et al. [7] described a radiologic scoring system for sarcoidosis which included several factors: reticulonodular (R), confluent (C), mass-like (M) and fibrotic (F) scores. This system is similar to others who have tried to assess the various aspects of parenchymal lung disease [53]. The Muers score was developed for a British Thoracic Society sarcoidosis study [14]. There was a significant improvement in the F score but not the $\mathrm{R}$ score for those treated with 18 months of therapy versus those who received only selective therapy [14]. In a trial of infliximab versus placebo, the R score significantly improved with infliximab therapy within 6 weeks of initiating therapy [28]. In a post hoc analysis, it was demonstrated that patients with a positive $\mathrm{R}$ score were significantly more likely to respond to infliximab while those with an $\mathrm{R}$ score equal to zero had no significant response to infliximab versus placebo [8].

While the Muers score may prove useful as a research tool, it requires a detailed reading of the films by someone who has been trained to use the score $[7,8]$. This is similar to the use of the International Labor Organization Classification for Pneumoconioses [54]. A more practical method is the comparison of the chest radiograph before and after intervention. This has proved to be reproducible $[8,9,55]$. In a large study of sarcoidosis patients followed with serial pulmonary function studies and chest radiography, ZAPPALA et al. [9] demonstrated that changes in chest radiography were superior to changes in stage when compared to pulmonary function studies. Changes in chest radiography have been reported in several trials. However, few studies have specified that the films were assessed in a blinded fashion and in a random order. Given the subjectivity of assessing changes in chest radiography [8], this would be an important component of ongoing studies.

While high resolution computed tomography has been used to assess lung disease in sarcoidosis [56,57], it has not been applied to assessing response to therapy in any clinical trial. One difficulty has been the lack of a standard approach that encompasses all the different aspects of the lung involvement [56].
Positron emission tomography scanning has been reported as changing during successful therapy with anti-tumour necrosis factor (TNF) agents $[10,58]$. This imaging technique is quite expensive and currently has not been widely applied. In addition, there is a significant radiation burden associated with the test. However, it may prove a useful measure in future studies. It should be noted that increased gallium activity is quickly suppressed by glucocorticoid therapy, and therefore serial studies have not been useful to monitor response to therapy [59].

\section{Quality of life}

Dyspnoea is usually the major indication for initiating therapy for pulmonary sarcoidosis. Dyspnoea can be assessed using the Medical Research Council (MRC) dyspnoea score [60]. Dyspnoea can also be assessed using the Borg scale [61], which is often measured before and after a 6-min walk test. MAHLER et al. [62] developed a transitional dyspnoea index, which has been used to measure response to an intervention. While all these instruments are useful, the most widely used has been the MRC dyspnoea score. It has been shown that the dyspnoea score only weakly correlates with FVC [52], chest radiography stage [52], or 6MWD [45]. This would indicate that the use of the MRC dyspnoea score may be a useful independent marker of disease. However, dyspnoea may be influenced by other factors, such as obesity and muscle weakness.

Several other quality of life instruments have been assessed in sarcoidosis. These include the general health status short form-36 (SF-36), the pulmonary specific St George's Respiratory Questionnaire, and the sarcoidosis specific Sarcoidosis Health Questionnaire [12]. Fatigue is an important aspect of sarcoidosis. There have been an increasing number of studies regarding sarcoidosis associated fatigue [63]. There was a correlation between fatigue and 6MWD [45]. Interestingly, a double-blind placebo-controlled randomised trial of D-methylphenidate for sarcoidosis associated fatigue found a significant improvement in FVC and some improvement in 6MWD for the active agent [50].

\section{Other measures}

Steroid sparing has been studied as an indication for treatment. While several drugs have been shown to be steroid sparing [15, $20,26,38]$, these studies did not use a standard criteria for reducing steroid dosage. In one study which did provide a standardised steroid tapering schedule, compliance was at best $90 \%$ among the multiple centres involved [18].

The idea of a composite score, which encompasses the various aspects of disease, has been used by some authors [14, 15]. This has the advantage of allowing measurement of several aspects of disease at the same time [5]. However, the composite score has not been validated in sarcoidosis and, therefore, it is unknown which features to include and their relative importance.

Angiotensin converting enzyme (ACE) has been proposed as a serum marker for response to therapy [64]. It has been reported in several clinical trials. However, ACE levels may be independently affected by treatment. For example, changes in ACE level are more immediately affected by changes in glucocorticoid dosage than by changes in clinical status of the patient $[65,66]$. Other serum markers such as soluble interleukin 2 are interesting, but have yet to be shown to be useful in monitoring 
response to therapy [67]. Chitotriosidase may prove to be a useful marker, but still needs to be evaluated [68]. Proteomic changes have also been reported with treatment with infliximab [34]. This broad base analysis may prove useful in future studies.

Changes in bronchoalveolar lavage (BAL) parameters during therapy may also be followed. Changes in release of TNF have been reported after treatment with corticosteroids, methotrexate and azathioprine [21, 69]. Changes in lymphocyte number and subpopulations have been reported after prednisone therapy $[69,70]$. However, these studies have been limited to subgroups of patients in larger clinical trials.

\section{INDIVIDUAL DRUGS FOR PULMONARY SARCOIDOSIS}

Figure 1 provides a general view of treatment for sarcoidosis for the various aspects of the disease. Specific recommendations regarding treatment have been made based on current evidence $[2,72]$. The overall approach to treatment depends on whether the patient has symptoms of dyspnoea or not. One also has to consider whether there are extrapulmonary manifestations that will require therapy. These include ocular, cardiac, hypercalcaemia, and neurologic disease [73]. For the symptomatic patient, one has to exclude other causes of symptoms. The patient may be short of breath with exertion because of pulmonary hypertension, cardiac, joint or muscle involvement, or even just fatigue [47]. These other manifestations may respond to the same anti-inflammatory treatments or respond to other treatment modalities [33]. For example, large airway obstruction may lead to significant dyspnoea. This condition responds best to anti-inflammatory therapy instituted within 6 months of onset. Prolonged obstruction is unlikely to respond to glucocorticoids [41]. Sarcoidosis associated pulmonary hypertension rarely responds to anti-inflammatory therapy, but some patients have had a significant improvement in symptoms with pulmonary vasodilator therapy [74]. Maintenance therapy has been used by some physicians to prevent recurrence of the disease $[75,76]$, but is not felt necessary by others. There are no randomised trials supporting its use. It is more commonly used for patients who have risk factors for chronic disease, such as those with neurologic or cardiac disease, lupus pernio, or advanced pulmonary disease.

\section{Glucocorticoids: the first step}

Glucocorticoid therapy has been the standard therapy for sarcoidosis for over 50 years. The usual initial dosage of glucocorticoids is $20-40 \mathrm{mg}$ per day prednisone, or its equivalent. The dose is then reduced by $50 \%$ every $6-8$ weeks, as tolerated, until a maintenance dosage of $5-10 \mathrm{mg}$ a day is achieved. The patient is then gradually weaned off the drug as tolerated $[18,77]$. Table 3 summarises clinical trials using these agents, including the clinical outcome. For patients with no symptoms and no evidence of parenchymal lung disease, there was no difference in treatment with corticosteroids versus placebo [16]. For patients with parenchymal lung disease on chest radiography but no symptoms, treatment for 18 months with glucocorticoids was better than placebo 5 years after initiation of therapy [14, 87]. This improvement was seen for the FVC [14, 87], changes in the F (fibrosis) score [14], and less dyspnoea [14]. Asymptomatic patients treated with glucocorticoids for 18 months were less likely to require glucocorticoids during the 32 month follow-up [87]. Some have argued that the changes with corticosteroid treatment did not justify the toxicity encountered with 18 months of corticosteroids. In one study, 17 of the 27 patients assigned to long term corticosteroids reported sideeffects with therapy versus only two of the 31 patients assigned to placebo [14]. In particular, weight gain was significantly higher for those who were treated with glucocorticoids. In this study, the average difference in spirometric values was only $9 \%$ and those who were assigned to placebo were still well within the normal range. Therefore, the toxicity of treatment seemed to be significantly more than any potential benefit.

The decision to treat symptomatic patients with corticosteroids is based on the above studies in the asymptomatic patients. In addition, there have been several studies which report the short and long term effectiveness of oral glucocorticoids in improving lung function $[17,75]$, although it is not clear that these benefits persist beyond the first year of treatment $[79,81]$.

One reason for the failure of glucocorticoids to maintain a prolonged improvement is toxicity. The usual approach to glucocorticoid treatment is to try to taper the drug dosage to a level which will maintain the patient with stable disease [75, 77]. In that situation, patients may require only short courses of increased dosage to manage episodes of deterioration [31]. However, the maintenance dosage may still be associated with significant toxicity and steroid sparing alternatives have been evaluated.

These include inhaled glucocorticoids. Budesonide, at doses of $800 \mu \mathrm{g}$ twice a day, has been shown to be effective at maintaining the improvement achieved with oral glucocorticoids [16]. However, not all studies found budesonide was effective in treating pulmonary disease [83]. Fluticasone at doses of 880$1000 \mu \mathrm{g}$ twice a day was not effective as steroid sparing for acute [18] or chronic pulmonary sarcoidosis [82]. Compared to placebo, inhaled glucocorticoids reduced the reported rate of cough $[18,82]$.

\section{Alternatives to glucocorticoids}

Several agents have been studied as steroid sparing alternatives [33]. Figure 1 summarises an approach by which many of these drugs have been studied for pulmonary sarcoidosis. Tables 3 and 4 summarise the clinical studies performed for pulmonary sarcoidosis in which adequate information could be extracted from the published reports to compare results between drugs. In some cases, where insufficient data was available from peer reviewed papers and case reports, letters to editors and abstracts were used to provide more information about potential new therapies for pulmonary sarcoidosis. In cases where pulmonary and extrapulmonary cases were combined in the report, the patients identified by the authors as having pulmonary disease are reported.

\section{Cytotoxic agents}

Methotrexate has been the most widely studied cytotoxic drug for pulmonary and extrapulmonary sarcoidosis [38, 88, 96-98]. There have been two large case series reporting efficacy in over $60 \%$ of patients with pulmonary disease $[38,88]$. In one series, 22 of 50 patients $(44 \%)$ had a greater than $10 \%$ improvement in their FVC after at least 1 year of methotrexate treatment [38]. A double-blind, placebo-controlled trial found that methotrexate was steroid sparing after 6 months of therapy and this 


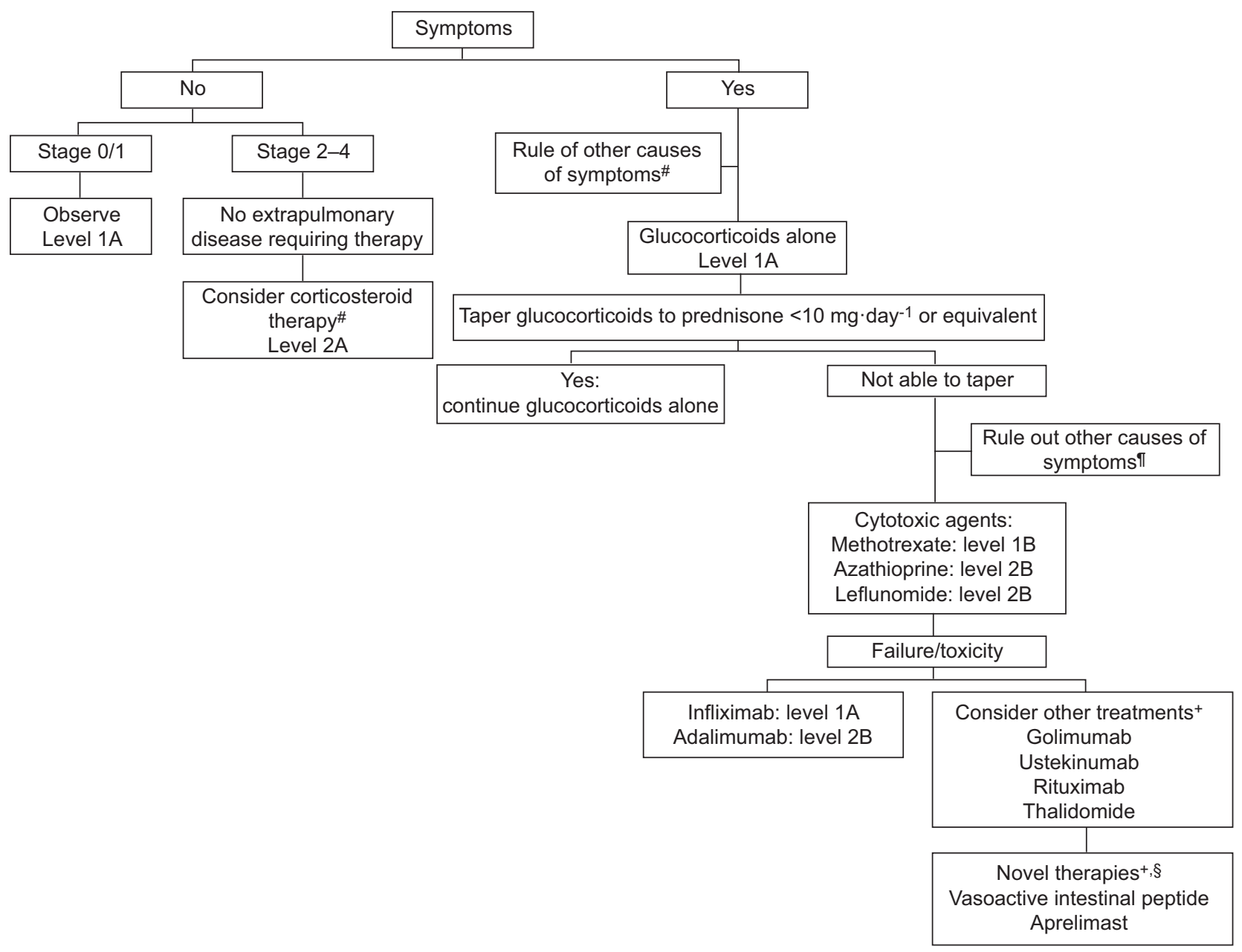

FIGURE 1. Proposed strategy for treating pulmonary disease. Evidence based recommendations where sufficient information is available. Recommendations are based on the following criteria [71]: level A: at least one double-blind, placebo-controlled trial with positive results with one or more case series supporting the results; level B: majority of the case series showing positive results; level $\mathrm{C}$ : case series with mixed reports of effectiveness or only a small number of case reports. Recommendations can be either strong $(1 \mathrm{~A}, 1 \mathrm{~B}, 1 \mathrm{C})$ or weak $(2 \mathrm{~A}, 2 \mathrm{~B}, 2 \mathrm{C})$. \#: for asymptomatic patients with persistent stage $2-4$ chest radiography, consider 3 months of systemic glucocorticoids followed by 15 months of high dose inhaled budesonide [16]; ": other causes of dyspnoea include pulmonary hypertension, congestive heart failure, infection and muscle weakness; ${ }^{+}$: these treatment options are based on a limited case series and/or a biological rationale for use, unable to provide a level of evidence; ${ }^{\varsigma}$ : novel therapies may not yet be available without a research protocol.

was associated with significantly less weight gain compared to the placebo group [20]. The most commonly encountered toxicity from methotrexate therapy includes nausea, mouth sores, and leukopenia. These are dose dependent and can be minimised with the addition of folic acid [99, 100]. Methotrexate can also lead to pulmonary toxicity [101] and unexplained cough should lead to evaluation for methotrexate toxicity. The frequency of hypersensitivity pneumonitis due to methotrexate appears to be approximately 5\% in rheumatoid arthritis [102, $103]$, but appears to be less in other conditions, including sarcoidosis [89]. Specific criteria for diagnosis have been developed [104]. When these were applied, life threatening interstitial lung disease from methotrexate was only 1\% [105]. Prolonged use of methotrexate can lead to hepatotoxicity. In rheumatoid arthritis, regular liver function testing has been useful in detecting methotrexate induced hepatotoxicity [106]. The value of regular liver function testing is less clear in sarcoidosis [107]. A persistent rise in transaminase liver testing in a sarcoidosis patient undergoing methotrexate therapy should lead to either discontinuation of drug or a liver biopsy.

Azathioprine has also been reported as effective in treating pulmonary and extrapulmonary sarcoidosis. The reports have been usually case series. In an open label study of 11 chronic pulmonary sarcoidosis patients, none had resolved or improved reticulonodular infiltrates with a combination of azathioprine and prednisolone [21]. For the whole group, there was a $14.4 \%$ improvement in the FVC. In another report of 35 patients treated with azathioprine, with other agents, $19(54 \%)$ were reported to have received some benefit from receiving the drug [89]. In one small series, azathioprine was not found to be steroid sparing in chronic pulmonary sarcoidosis [90]. Azathioprine is associated with nausea and leukopenia. Azathioprine is metabolised by thiopurine S-methyltransferase (TPMT). Patients with low or deficient TPMT levels can develop severe toxicity [108]. Measurement of TPMT levels or close monitoring of blood counts 


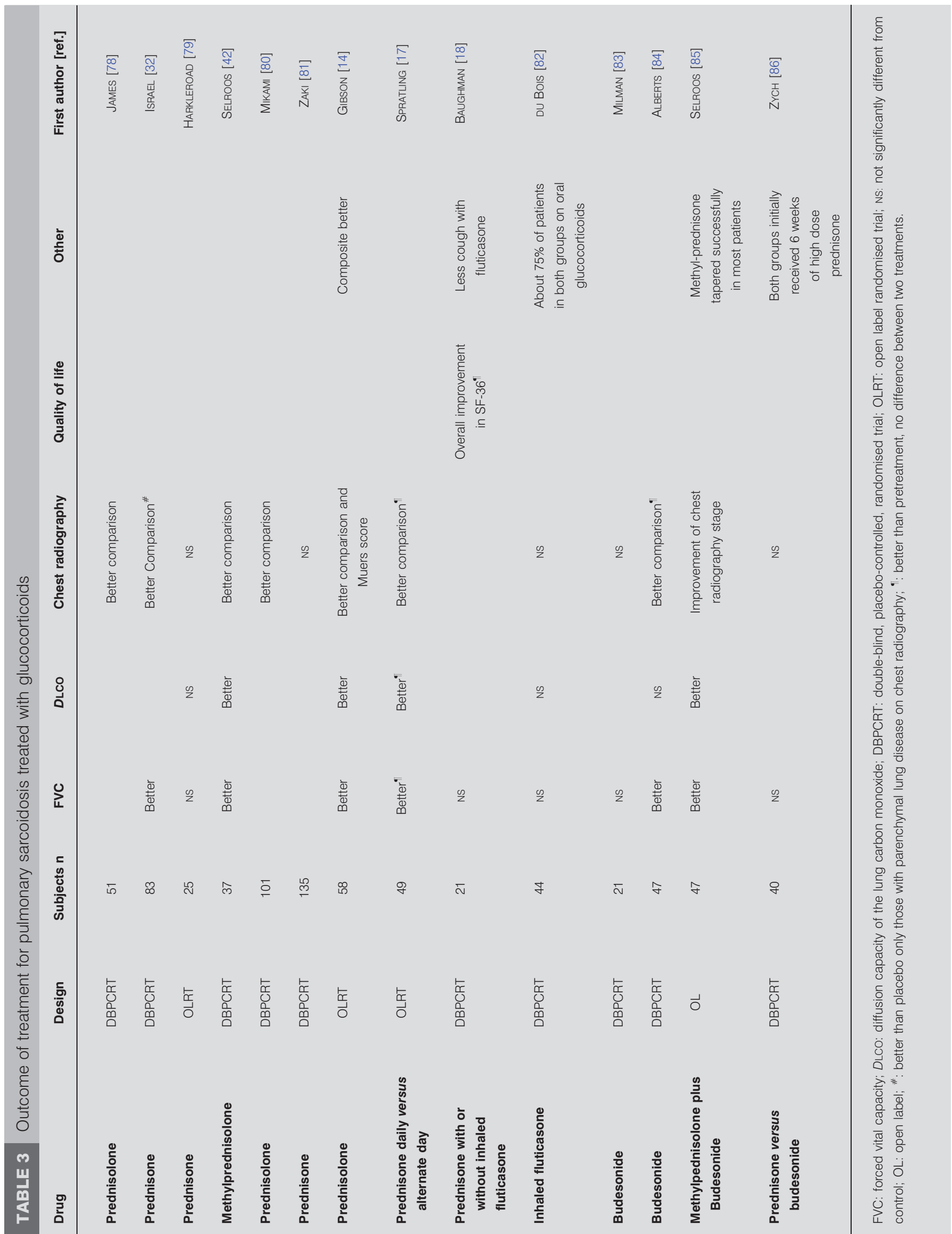




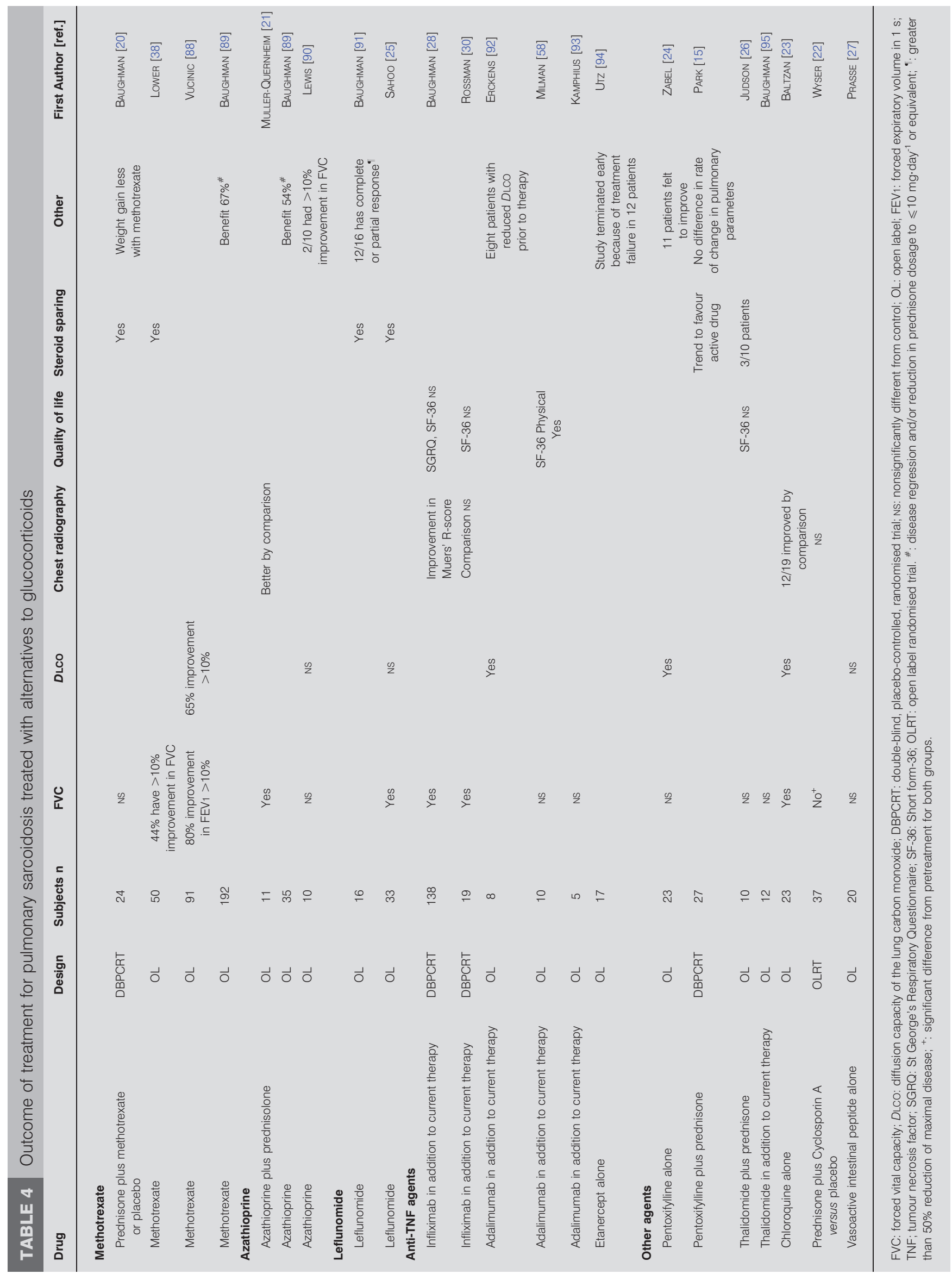


should be used to avoid this toxicity. Rarely, azathioprine can lead to severe hepatotoxicity [109].

Leflunomide was developed as an alternative to methotrexate for rheumatoid arthritis [110]. It can be given alone or in combination with methotrexate [111]. It has been reported as effective in treating sarcoidosis in two case series [25, 91]. Table 4 summarises the patients who were treated for pulmonary disease in those series. In the study by SAHOO et al. [25], they found a significant improvement in FVC from pretreatment values. Major toxicities are similar to methotrexate. In comparison to the control group of 198 sarcoidosis patients treated with methotrexate alone, there was no difference in hepatic or haematological changes during long term monitoring [91]. In examining all 78 patients treated with leflunomide at their institution, eight were found to have developed symptoms suggestive of lower respiratory infections [25]. However, it may be difficult to distinguish infection from therapy versus underlying disease. In an analysis of rheumatoid arthritis patients receiving leflunomide, three out of 171 developed lower respiratory tract infections [112]. Systemic hypertension can also occur with leflunomide [105]. Peripheral neuropathy has been reported with the drug and may require cholestyramine or other treatment to enhance withdrawal of the drug [113].

Pulmonary toxicity has been reported with leflunomide, but at a lower rate than that reported with methotrexate $[105,114$, 115]. In a post-marketing survey in Japan, $1.2 \%$ of patients treated with leflunomide were reported to have developed interstitial lung disease [116]. In rheumatoid arthritis, the presence of pretreatment for interstitial lung disease was a risk factor for developing fatal pulmonary toxicity [117]. Prior or concurrent therapy with methotrexate was also a risk factor for developing pneumonitis [114, 116]. Sarcoidosis patients who develop an intractable cough while receiving methotrexate have been successfully treated with leflunomide with no further pulmonary symptoms [91].

\section{Anti-TNF agents}

For some patients with sarcoidosis, glucocorticoid steroid therapy may not control disease. In some of these patients, excessive production of TNF by alveolar macrophages, retrieved by BAL, has been reported [118]. Several biological agents which specifically inhibit TNF have become commercially available and have been studied in sarcoidosis [119]. These have been reported as effective in treating sarcoidosis patients, especially in those for whom other treatments fail [120-122]. These initial reports led to two double-blind, placebo-controlled trials of infliximab in patients with chronic pulmonary sarcoidosis [28, 30]. The larger of these studies compared 45 placebo treated patients to 93 patients treated with two different doses of infliximab [28]. All patients were stable on prednisone and/or other anti-inflammatory drugs. There was a significant improvement in FVC seen within 6 weeks of initiating therapy. There was also a significant improvement in the R-score of the chest radiography. A subsequent analysis did not find a significant difference in the global assessment for those treated with placebo versus infliximab. However, there was a significant correlation between the change in global assessment and change in FVC [8]. Subgroup analysis of this trial found that CRP predicted the response to therapy. For patients with an elevated CRP level, 24 weeks of treatment led to a $>5 \%$ change of FVC \% predicted between the infliximab and the placebo groups. This was associated with a significant improvement in 6MWD and dyspnoea score [29].

In the other randomised trial of infliximab, there was no significant difference between the placebo and infliximab treated patients [30]. This study included an open label arm with all patients receiving the drug after 6 weeks. As noted above, infliximab had been shown to significantly improve FVC by 6 weeks. When an analysis was performed of the change in FVC from baseline to 6 weeks after the first two doses of infliximab, a significant improvement was seen.

Adalimumab is a humanised monoclonal antibody associated with a lower rate of allergic reactions than infliximab. It had been reported to improve outcomes in half of 27 patients treated at one institution, which was lower than the response reported with infliximab [123]. However, that report used the dosage suggested for rheumatoid arthritis. For Crohn's disease, a higher loading and maintenance dose has been found to be associated with a higher rate of response [124, 125]. Since both sarcoidosis and Crohn's disease are granulomatous conditions, it seems logical to follow the regimen developed for Crohn's disease. Several open label studies have employed a higher dose of adalimumab [56, 92, 93]. These studies have reported an improvement with treatment. Golimumab is a recently developed humanised monoclonal antibody directed against TNF and was associated with less adverse events than other anti-TNF agents [126]. In a recently completed randomised double-blind placebo-controlled trial, the drug was not found to be more effective than placebo for pulmonary sarcoidosis. The effectiveness of golimumab for cutaneous disease, and whether higher doses of the drug may be effective for pulmonary disease are being analysed.

Etanercept is a TNF receptor antagonist. It had been reported as effective in treating some cases of refractory sarcoidosis [127]. In an open label trial of pulmonary disease, UTz et al. [94] found that treatment with etanercept alone was associated with treatment failure in 12 out of 17 cases. The drug was not found to be effective in a double-blind placebo-controlled trial of patients with refractory sarcoidosis uveitis [128]. The poor response rate for etanercept in sarcoidosis was similar to that found in larger trials using the drug for Crohn's disease [129].

Similar toxicities have been reported for all the anti-TNF agents [130]. These include allergic reactions to the agents. This is more likely to occur with infliximab, since it is a chimeric antibody while adalimumab is a humanised antibody. However, lupus like reactions have been reported with both drugs [131]. For infliximab, the concurrent use of methotrexate or other cytotoxic drugs has been recommended to reduce the risk of antibodies directed against infliximab [119].

Since these agents cause regression of granulomas, there is a marked increased risk for reactivation of tuberculosis associated with their use [132, 133]. Prior to starting anti-TNF therapy, screening for latent tuberculosis has been associated with a reduced risk for active tuberculosis during therapy [134]. The quantinterferon test may be more specific and sensitive in detecting latent tuberculosis, and may be helpful in the patient with known anergy (a common occurrence in sarcoidosis) [135]. Other infections, including routine bacterial 
infections, occur at a higher rate in anti-TNF treated patients compared to controls [136].

As a group, one has to consider the less frequent, but significant, risks associated with anti-TNF therapy. These include worsening of congestive heart failure [137], cases of demyelinating disease [138], and potential increased risk for malignancy [139]. The latter is still controversial, with a recent meta-analysis failing to demonstrate an increased risk of lymphoma in rheumatoid arthritis patients treated with anti-TNF therapy [140]. It has been recommended that anti-TNF agents, such as infliximab, be given with low dose methotrexate or azathioprine [119]. This is, in part, to minimise the risk for allergic reactions to the anti-TNF agent and increase blood levels of infliximab [141]. The use of infliximab with azathioprine in inflammatory bowel disease seems to be associated with a small increase in the rate of lymphoma, but it is unclear whether it is due to the combination of drugs or the underlying disease [139, 142].

Interestingly, there have been several reports of sarcoidosis-like reactions occurring during treatment with anti-TNF therapy [143-145]. In one series, half of the cases were associated with etanercept therapy [146]. The mechanism of action here appears complex, but suggests that a patient who is failing anti-TNF therapy should have the drug withdrawn rather than simply adding another agent.

\section{Other agents}

Pentoxifylline was first reported as effective in treating acute pulmonary sarcoidosis in an open label trial by ZABEL et al. [24]. There was a statistically significant improvement in the DLCO, although there was no significant change in FVC for the group. In a double-blind, placebo-controlled trial, PARK et al. [15] reported no change in a composite score, used to assess response to therapy, in those treated with pentoxifylline versus controls. However, there was a trend for the drug to be steroid sparing. The drug is associated with significant gastrointestinal toxicity, especially at the doses reported by these authors [15, 24]. This has limited its utility in treating chronic pulmonary disease. A new phosphodiesterase inhibitor, apremilast, has been reported as effective for chronic cutaneous sarcoidosis [147]. The drug has not yet been reported in the treatment of pulmonary sarcoidosis.

Thalidomide had been first reported as effective in treating chronic cutaneous sarcoidosis [148]. In an open label, dose escalation trial of thalidomide in sarcoidosis patients with lupus pernio, there was no significant improvement in the FVC with therapy [26]. In a more detailed study of pulmonary sarcoidosis patients on chronic prednisone, thalidomide was not associated with improvement of either FVC or SF-36. However, the drug was steroid sparing in some cases. Thalidomide has severe teratogenic effects. In addition, at the doses used to treat sarcoidosis, constipation, hypersomnulance, and peripheral neuropathy are often dose limiting side-effects [95]. There is an increased risk for deep venous thrombosis and pulmonary embolism, which may be reduced by the use of anti-thrombotic agents [149].

Chloroquine has been used for both cutaneous and pulmonary sarcoidosis [150, 151]. In a prospective, open label trial, BALTZAN et al. [23] demonstrated a small but significant improvement in pulmonary function and chest radiography with high dose therapy in chronic pulmonary sarcoidosis patients.
In an extension of the study, patients treated with low dose chloroquine had a slower progression of decline of their disease compared to those receiving placebo [23]. Chloroquine is associated with significant gastrointestinal and ocular toxicity, which is dose dependent [152]. Hydroxychloroquine has been preferred by many physicians, but one still has to monitor for ocular toxicity [153]. Toxicity is also dose dependent and dosage should be adjusted based on patient weight [154, 155].

Cyclosporin A has dramatic effect on the CD-4 T-cell. In some case reports, it was felt to be effective for refractory disease [156]. In a double-blind, randomised trial of chronic pulmonary sarcoidosis, WYSER et al. [22] found no significant additional benefit for adding cyclosporin A to prednisone therapy in terms of either pulmonary function or steroid sparing. The drug was associated with significant toxicity, including: hypertension, renal dysfunction, increased risk for opportunistic infections, and malignancy. Because of these complications, the drug is rarely used to treat pulmonary sarcoidosis.

An interesting study by PRASSE et al. [27] reported on treatment of pulmonary sarcoidosis with inhaled vasoactive intestinal peptide. Treatment with vasoactive intestinal peptide was associated with significant changes in the release of several cytokines by alveolar macrophages retrieved by BAL. However, they were not able to demonstrate a change in the FVC [27]. However, this was a proof of concept study with a relatively small number of patients and relatively short follow-up. The drug was well tolerated. It did require a large number of treatments per day, which may limit its application in the reported administrative route. However, future studies do seem warranted.

Rituximab is a monoclonal antibody directed again CD-20 cells. It has been reported as effective for refractory sarcoidosis in case reports [157-160]. The drug has significant toxicity, including reactions to infusion and increased risk for infections [159, 161]. As opposed to anti-TNF agents, the risk appears to be for viral infections, such as hepatitis B, cytomegalovirus and CreutzfeldtJakob [162]. The latter is associated with an increased risk for progressive multifocal leukoencephalopathy [163].

Ustekinumab is an anti-interleukin 12 and interleukin 23 monoclonal antibody which has been shown to be safe and effective for psoriasis for up to 3 years [164]. Since these cytokines are important in chronic sarcoidosis [165], there is a rationale for study of this drug in sarcoidosis. In a recently completed randomised double-blind placebo-controlled trial, the drug was not effective for pulmonary sarcoidosis at the doses employed.

\section{CONCLUSION}

While many patients with pulmonary sarcoidosis do not require therapy, there are a significant number who require long term therapy. For most patients, corticosteroids represent the best initial treatment. However, steroid sparing agents have been increasingly useful for the long term management of these patients, despite the lack of standardised measures to assess such therapy in large randomised double-blind placebocontrolled trials. Despite the lack of Food and Drug Administration approved therapy for sarcoidosis, the introduction of powerful biological agents which block cytokines, such as TNF, expanded the options available for refractory cases. Newer 
biological agents are being studied for this disease. As these drugs become more widely available, it is important to implement the translational approach to clinical trials, and develop standardised outcome measures for various disease phenotypes. A team approach aiming to provide a comprehensive, translational, clinical, economic and personalised approach may serve patients best.

\section{STATEMENT OF INTEREST}

Conflict of interest information can be found alongside the online version of this article at www.erj.ersjournals.com

\section{REFERENCES}

1 Bradley B, Branley HM, Egan JJ, et al. Interstitial lung disease guideline: the British Thoracic Society in collaboration with the Thoracic Society of Australia and New Zealand and the Irish Thoracic Society. Thorax 2008; 63: Suppl. 5, v1-v58.

2 Baughman RP, Nunes H. Therapy for sarcoidosis: evidencebased recommendations. Expert Rev Clin Immunol 2012; 8: 95-103.

3 Paramothayan S, Jones PW. Corticosteroid therapy in pulmonary sarcoidosis: a systematic review. JAMA 2002; 287: 1301-1307.

4 Paramothayan S, Lasserson T, Walters EH. Immunosuppressive and cytotoxic therapy for pulmonary sarcoidosis. Cochrane Database Syst Rev 2003; CD003536.

5 Keir G, Wells AU. Assessing pulmonary disease and response to therapy: which test? Semin Respir Crit Care Med 2010; 31: 409-418.

6 Scadding JG. Prognosis of intrathoracic sarcoidosis in England. Br Med J 1961; 2: 1165-1172.

7 Muers MF, Middleton WG, Gibson GJ, et al. A simple radiographic scoring method for monitoring pulmonary sarcoidosis: relations between radiographic scores, dyspnoea grade and respiratory function in the British Thoracic Society study of longterm corticosteroid treatment. Sarcoidosis Vasc Diffuse Lung Dis 1997; 14: 46-56.

8 Baughman RP, Shipley R, Desai S, et al. Changes in chest roentgenogram of sarcoidosis patients during a clinical trial of infliximab therapy: comparison of different methods of evaluation. Chest 2009; 136: 526-535.

9 Zappala CJ, Desai SR, Copley SJ, et al. Optimal scoring of serial change on chest radiography in sarcoidosis. Sarcoidosis Vasc Diffuse Lung Dis 2011; 28: 130-138.

10 Keijsers RG, Verzijlbergen JF, van Diepen DM, et al. 18F-FDG PET in sarcoidosis: an observational study in 12 patients treated with infliximab. Sarcoidosis Vasc Diffuse Lung Dis 2008; 25: 143-149.

11 Teirstein AS, Machac J, Almeida O, et al. Results of 188 wholebody fluorodeoxyglucose positron emission tomography scans in 137 patients with sarcoidosis. Chest 2007; 132: 1949-1953.

12 Cox CE, Donohue JF, Brown CD, et al. The sarcoidosis health questionnaire. A new measure of health-related quality of life. Am J Resp Crit Care Med 2003; 168: 323-329.

13 de Vries J, Michielsen H, van Heck GL, et al. Measuring fatigue in sarcoidosis: the Fatigue Assessment Scale (FAS). Br J Health Psychol 2004; 9: 279-291.

14 Gibson GJ, Prescott RJ, Muers MF, et al. British Thoracic Society Sarcoidosis study: effects of long term corticosteroid treatment. Thorax 1996; 51: 238-247.

15 Park MK, Fontana JR, Babaali H, et al. Steroid sparing effects of pentoxifylline in pulmonary sarcoidosis. Sarcoidosis Vasc Diffuse Lung Dis 2009; 26: 121-131.

16 Pietinalho A, Tukiainen $\mathrm{P}$, Haahtela $\mathrm{T}$, et al. Oral prednisolone followed by inhaled budesonide in newly diagnosed pulmonary sarcoidosis: a double-blind, placebo-controlled, multicenter study. Chest 1999; 116: 424-431.
17 Spratling L, Tenholder MF, Underwood GH, et al. Daily vs alternate day prednisone therapy for stage II sarcoidosis. Chest 1985; 88: 687-690.

18 Baughman RP, Iannuzzi MC, Lower EE, et al. Use of fluticasone in acute symptomatic pulmonary sarcoidosis. Sarcoidosis Vasc Diffuse Lung Dis 2002; 19: 198-204.

19 du Bois RM, Weycker D, Albera C, et al. Forced vital capacity in patients with idiopathic pulmonary fibrosis: test properties and minimal clinically important difference. Am J Respir Crit Care Med 2011; 184: 1382-1389.

20 Baughman RP, Winget DB, Lower EE. Methotrexate is steroid sparing in acute sarcoidosis: results of a double blind, randomized trial. Sarcoidosis Vasc Diffuse Lung Dis 2000; 17: 60-66.

21 Muller-Quernheim J, Kienast K, Held M, et al. Treatment of chronic sarcoidosis with an azathioprine/prednisolone regimen. Eur Respir J 1999; 14: 1117-1122.

22 Wyser CP, van Schalkwyk EM, Alheit B, et al. Treatment of progressive pulmonary sarcoidosis with cyclosporin A: a randomized controlled trial. Am J Respir Crit Care Med 1997; 156: 1371-1376.

23 Baltzan M, Mehta S, Kirkham TH, et al. Randomized trial of prolonged chloroquine therapy in advanced pulmonary sarcoidosis. Am J Respir Crit Care Med 1999; 160: 192-197.

24 Zabel P, Entzian P, Dalhoff K, et al. Pentoxifylline in treatment of sarcoidosis. Am J Respir Crit Care Med 1997; 155: 1665-1669.

25 Sahoo DH, Bandyopadhyay D, Xu M, et al. Effectiveness and safety of leflunomide for pulmonary and extrapulmonary sarcoidosis. Eur Respir J 2011; 38: 1145-1150.

26 Judson MA, Silvestri J, Hartung C, et al. The effect of thalidomide on corticosteroid-dependent pulmonary sarcoidosis. Sarcoidosis Vasc Diffuse Lung Dis 2006; 23: 51-57.

27 Prasse A, Zissel G, Lützen N, et al. Inhaled vasoactive intestinal peptide exerts immunoregulatory effects in sarcoidosis. Am J Respir Crit Care Med 2010; 182: 540-548.

28 Baughman RP, Drent M, Kavuru M, et al. Infliximab therapy in patients with chronic sarcoidosis and pulmonary involvement Am J Respir Crit Care Med 2006; 174: 795-802.

29 Sweiss NJ, Barnathan ES, Lo K, et al. C-reactive protein predicts response to infliximab in patients with chronic sarcoidosis Sarcoidosis Vasc Diffuse Lung Dis 2010; 27: 49-56.

30 Rossman MD, Newman LS, Baughman RP, et al. A double-blind, randomized, placebo-controlled trial of infliximab in patients with active pulmonary sarcoidosis. Sarcoidosis Vasc Diffuse Lung Dis 2006; 23: 201-208.

31 McKinzie BP, Bullington WM, Mazur JE, et al. Efficacy of shortcourse, low-dose corticosteroid therapy for acute pulmonary sarcoidosis exacerbations. Am J Med Sci 2010; 339: 1-4.

32 Israel HL, Fouts DW, Beggs RA. A controlled trial of prednisone treatment of sarcoidosis. Am Rev Respir Dis 1973; 107: 609-614.

33 Baughman RP, Costabel U, du Bois RM. Treatment of sarcoidosis. Clin Chest Med 2008; 29: 533-548.

34 Loza MJ, Brodmerkel C, du Bois RM, et al. Inflammatory profile and response to anti-tumor necrosis factor therapy in patients with chronic pulmonary sarcoidosis. Clin Vaccine Immunol 2011; 18: 931-939.

35 Zappala CJ, Latsi PI, Nicholson AG, et al. Marginal decline in forced vital capacity is associated with a poor outcome in idiopathic pulmonary fibrosis. Eur Respir J 2010; 35: 830-836.

36 Noble PW, Albera C, Bradford WZ, et al. Pirfenidone in patients with idiopathic pulmonary fibrosis (CAPACITY): two randomised trials. Lancet 2011; 377: 1760-1769.

37 Tashkin DP, Elashoff R, Clements PJ, et al. Cyclophosphamide versus placebo in scleroderma lung disease. $N$ Engl J Med 2006; 354: 2655-2666.

38 Lower EE, Baughman RP. Prolonged use of methotrexate for sarcoidosis. Arch Intern Med 1995; 155: 846-851. 
39 Sharma OP, Johnson R. Airway obstruction in sarcoidosis. A study of 123 nonsmoking black American patients with sarcoidosis. Chest 1988; 94: 343-346.

40 Lavergne F, Clerici C, Sadoun D, et al. Airway obstruction in bronchial sarcoidosis: outcome with treatment. Chest 1999; 116: 1194-1199.

41 Chambellan A, Turbie P, Nunes H, et al. Endoluminal stenosis of proximal bronchi in sarcoidosis: bronchoscopy, function, and evolution. Chest 2005; 127: 472-481.

42 Selroos O, Sellergren TL. Corticosteroid therapy of pulmonary sarcoidosis. Scand J Respir Dis 1979; 60: 215-221.

43 Sulica R, Teirstein AS, Kakarla S, et al. Distinctive clinical, radiographic, and functional characteristics of patients with sarcoidosis-related pulmonary hypertension. Chest 2005; 128 : 1483-1489.

44 Baughman RP, Engel PJ, Meyer CA, et al. Pulmonary hypertension in sarcoidosis. Sarcoidosis Vasc Diffuse Lung Dis 2006; 23: 108-116.

45 Baughman RP, Sparkman BK, Lower EE. Six-minute walk test and health status assessment in sarcoidosis. Chest 2007; 132: 207-213.

46 Eaton T, Young P, Milne D, et al. Six-minute walk, maximal exercise tests: reproducibility in fibrotic interstitial pneumonia. Am J Respir Crit Care Med 2005; 171: 1150-1157.

47 Baughman RP, Lower EE. Six-minute walk test in managing and monitoring sarcoidosis patients. Curr Opin Pulm Med 2007; 13 439-444.

48 Judson MA, Highland KB, Kwon S, et al. Ambrisentan for sarcoidosis associated pulmonary hypertension. Sarcoidosis Vasc Diffuse Lung Dis 2011; 28: 139-145.

49 Baughman RP, Judson MA, Lower EE, et al. Inhaled iloprost for sarcoidosis associated pulmonary hypertension. Sarcoidosis Vasc Diffuse Lung Dis 2009; 26: 110-120.

50 Lower EE, Harman S, Baughman RP. Double-blind, randomized trial of dexmethylphenidate hydrochloride for the treatment of sarcoidosis associated fatigue. Chest 2008; 133: 1189-1195.

51 DeRemee RA. The roentgenographic staging of sarcoidosis. Historic and contemporary perspectives. Chest 1983; 83: 128-133.

52 Yeager H, Rossman MD, Baughman RP, et al. Pulmonary and psychosocial findings at enrollment in the ACCESS study. Sarcoidosis Vasc Diffuse Lung Dis 2005; 22: 147-153.

53 McLoud TC, Epler GR, Gaensler EA, et al. A radiographic classification for sarcoidosis: physiologic correlation. Invest Radiol 1982; 17: 129-138.

54 Welch LS, Hunting KL, Balmes J, et al. Variability in the classification of radiographs using the 1980 International Labor Organization Classification for Pneumoconioses. Chest 1998; 114 1740-1748

55 Judson MA, Gilbert GE, Rodgers JK, et al. The utility of the chest radiograph in diagnosing exacerbations of pulmonary sarcoidosis. Respirology 2008; 13: 97-102.

56 Oberstein A, von Zitzewitz H, Schweden F, et al. Non invasive evaluation of the inflammatory activity in sarcoidosis with highresolution computed tomography. Sarcoidosis Vasc Diffuse Lung Dis 1997; 14: 65-72.

57 Hansell DM, Milne DG, Wilsher ML, et al. Pulmonary sarcoidosis: morphologic associations of airflow obstruction at thinsection CT. Radiology 1998; 209: 697-704.

58 Milman N, Graudal N, Loft A, et al. Effect of the TNF- $\alpha$ inhibitor adalimumab in patients with recalcitrant sarcoidosis: a prospective observational study using FDG-PET. Clin Respir J 2012; 6 : 238-247.

59 Baughman RP, Shipley R, Eisentrout CE. Predictive value of gallium scan, angiotensin-converting enzyme level, and bronchoalveolar lavage in two-year follow-up of pulmonary sarcoidosis. Lung 1987; 165: 371-377.
60 Bestall JC, Paul EA, Garrod R, et al. Usefulness of the Medical Research Council (MRC) dyspnoea scale as a measure of disability in patients with chronic obstructive pulmonary disease. Thorax 1999; 54: 581-586

61 Borg G. Psychophysical bases of perceived exertion. Med Sci Sports Exerc 1982; 14: 377-381.

62 Mahler DA, Weinberg DH, Wells CK, et al. The measurement of dyspnea. Contents, interobserver agreement, and physiologic correlates of two new clinical indexes. Chest 1984; 85: 751-758.

63 de Kleijn WP, de Vries J, Lower EE, et al. Fatigue in sarcoidosis: a systematic review. Curr Opin Pulm Med 2009; 15: 499-506.

64 DeRemee RA, Rohrbach MS. Serum angiotensin-converting enzyme in evaluating the clinical course of sarcoidosis. Ann Intern Med 1980; 92: 361-365.

65 Baughman RP, Ploysongsang Y, Roberts RD, et al. Effects of sarcoid and steroids on angiotensin-converting enzyme. Am Rev Respir Dis 1983; 128: 631-633.

66 Grönhagen-Riska C, Selroos O, Niemisto M. Angiotensin converting enzyme. V. Serum levels as monitors of disease activity in corticosteroid-treated sarcoidosis. Eur J Respir Dis 1980; 61: 113-122.

67 Bargagli E, Mazzi A, Rottoli P. Markers of inflammation in sarcoidosis: blood, urine, BAL, sputum, and exhaled gas. Clin Chest Med 2008; 29: 445-458.

68 Bargagli E, Maggiorelli C, Rottoli P. Human chitotriosidase: a potential new marker of sarcoidosis severity. Respiration 2008; 76 234-238.

69 Baughman RP, Lower EE. The effect of corticosteroid or methotrexate therapy on lung lymphocytes and macrophages in sarcoidosis. Am Rev Respir Dis 1990; 142: 1268-1271.

70 Pinkston P, Saltini C, Muller-Quernheim J, et al. Corticosteroid therapy suppresses spontaneous interleukin 2 release and spontaneous proliferation of lung T lymphocytes of patients with active pulmonary sarcoidosis. J Immunol 1987; 139: 755-760.

71 Guyatt G, Gutterman D, Baumann MH, et al. Grading strength of recommendations and quality of evidence in clinical guidelines: report from an American College of Chest Physicians Task Force. Chest 2006; 129: 174-181.

72 Baughman RP, Culver DA, Judson MA. A concise review of pulmonary sarcoidosis. Am J Respir Crit Care Med 2011; 183 573-581.

73 Hunninghake GW, Costabel U, Ando M, et al. ATS/ERS/ WASOG statement on sarcoidosis. American Thoracic Society/ European Respiratory Society/World Association of Sarcoidosis and other Granulomatous Disorders. Sarcoidosis Vasc Diffuse Lung Dis 1999; 16: 149-173.

74 Palmero V, Sulica R. Sarcoidosis-associated pulmonary hypertension: assessment and management. Semin Respir Crit Care Med 2010; 31: 494-500.

75 Johns CJ, Michele TM. The clinical management of sarcoidosis: a 50-year experience at the Johns Hopkins hospital. Medicine 1999; 78: 65-111.

76 Gottlieb JE, Israel HL, Steiner RM, et al. Outcome in sarcoidosis. The relationship of relapse to corticosteroid therapy. Chest 1997; 111: 623-631.

77 Judson MA. An approach to the treatment of pulmonary sarcoidosis with corticosteroids: the six phases of treatment. Chest 1999; 115: 1158-1165.

78 James DG, Carstairs LS, Trowell J, et al. Treatment of sarcoidosis. Report of a controlled therapeutic trial. Lancet 1967; 2: 526-528.

79 Harkleroad LE, Young RL, Savage PJ, et al. Pulmonary sarcoidosis. Long-term follow-up of the effects of steroid therapy. Chest 1982; 82: 84-87.

80 Mikami R, Hiraga Y, Iwai K, et al. A double-blind controlled trial on the effect of corticosteroid therapy in sarcoidosis. In: Iwai K, 
Hosoda Y, eds. Proceedings of the VI International Conference on Sarcoidosis. Tokyo, University of Tokyo Press, 1974; pp. 533-538.

81 Zaki MH, Lyons HA, Leilop L, et al. Corticosteroid therapy in sarcoidosis: a five year controlled follow-up. NY State J Med 1987; 87: 496-499.

82 du Bois RM, Greenhalgh PM, Southcott AM, et al. Randomized trial of inhaled fluticasone propionate in chronic stable pulmonary sarcoidosis: a pilot study. Eur Respir J 1999; 13: 1345-1350.

83 Milman N, Graudal N, Grode G, et al. No effect of high-dose inhaled steroids in pulmonary sarcoidosis: a double-blind, placebo-controlled study. J Intern Med 1994; 236: 285-290.

84 Alberts C, van der Mark TW, Jansen HM. Inhaled budesonide in pulmonary sarcoidosis: a double-blind, placebo-controlled study. Dutch Study Group on Pulmonary Sarcoidosis. Eur Respir J 1995; 8: 682-688.

85 Selroos O, Löfroos AB, Pietinalho A, et al. Inhaled budesonide for maintenance treatment of pulmonary sarcoidosis. Sarcoidosis 1994; 11: 126-131.

86 Zych D, Pawlicka L, Zielinski J. Inhaled budesonide vs prednisone in the maintenance treatment of pulmonary sarcoidosis. Sarcoidosis 1993; 10: 56-61.

87 Pietinalho A, Tukiainen P, Haahtela T, et al. Early treatment of stage II sarcoidosis improves 5-year pulmonary function. Chest 2002; 121: 24-31.

88 Vucinic VM. What is the future of methotrexate in sarcoidosis? A study and review. Curr Opin Pulm Med 2002; 8: 470-476.

89 Baughman RP, Lower EE. Alternatives to corticosteroids in the treatment of sarcoidosis. Sarcoidosis 1997; 14: 121-130.

90 Lewis SJ, Ainslie GM, Bateman ED. Efficacy of azathioprine as second-line treatment in pulmonary sarcoidosis. Sarcoidosis Vasc Diffuse Lung Dis 1999; 16: 87-92.

91 Baughman RP, Lower EE. Leflunomide for chronic sarcoidosis. Sarcoidosis Vasc Diffuse Lung Dis 2004; 21: 43-48.

92 Erckens RJ, Mostard RL, Wijnen PA, et al. Adalimumab successful in sarcoidosis patients with refractory chronic noninfectious uveitis. Graefes Arch Clin Exp Ophthalmol 2012; 250: 713-720.

93 Kamphuis LS, Lam-Tse WK, Dik WA, et al. Efficacy of adalimumab in chronically active and symptomatic patients with sarcoidosis. Am J Respir Crit Care Med 2011; 184: 1214-1216.

94 Utz JP, Limper AH, Kalra S, et al. Etanercept for the treatment of stage II and III progressive pulmonary sarcoidosis. Chest 2003; 124: 177-185.

95 Baughman RP, Judson MA, Teirstein AS, et al. Thalidomide for chronic sarcoidosis. Chest 2002; 122: 227-232.

96 Lower EE, Baughman RP. The use of low dose methotrexate in refractory sarcoidosis. Am J Med Sci 1990; 299: 153-157.

97 Gedalia A, Molina JF, Ellis GS, et al. Low-dose methotrexate therapy for childhood sarcoidosis. J Pediatr 1997; 130: 25-29.

98 Israel HL. The treatment of sarcoidosis. Postgrad Med J 1970; 46: 537-540.

99 Morgan SL, Baggott JE, Vaughn WH, et al. Supplementation with folic acid during methotrexate therapy for rheumatoid arthritis. A double-blind, placebo-controlled trial. Ann Intern Med 1994; 121: 833-841.

100 Morgan SL, Baggott JE. Folate supplementation during methotrexate therapy for rheumatoid arthritis. Clin Exp Rheumatol 2010; 28: Suppl. 61, S102-S109.

101 Zisman DA, McCune WJ, Tino G, et al. Drug-induced pneumonitis: the role of methotrexate. Sarcoidosis Vasc Diffuse Lung Dis 2001; 18: 243-252.

102 Imokawa S, Colby TV, Leslie KO, et al. Methotrexate pneumonitis: review of the literature and histopathological findings in nine patients. Eur Respir J 2000; 15: 373-381.
103 Kremer JM, Alarcón GS, Weinblatt ME, et al. Clinical, laboratory, radiographic, and histopathologic features of methotrexateassociated lung injury in patients with rheumatoid arthritis: a multicenter study with literature review. Arthritis Rheum 1997; 40: 1829-1837.

104 Searles G, McKendry RJ. Methotrexate pneumonitis in rheumatoid arthritis: potential risk factors. Four case reports and a review of the literature. J Rheumatol 1987; 14: 1164-1171.

105 Emery P, Breedveld FC, Lemmel EM, et al. A comparison of the efficacy and safety of leflunomide and methotrexate for the treatment of rheumatoid arthritis. Rheumatology (Oxford) 2000; 39: 655-665.

106 Kremer JM, Alarcón GS, Lightfoot RW Jr, et al. Methotrexate for rheumatoid arthritis. Suggested guidelines for monitoring liver toxicity. American College of Rheumatology. Arthritis Rheum 1994; 37: 316-328.

107 Baughman RP, Koehler A, Bejarano PA, et al. Role of liver function tests in detecting methotrexate-induced liver damage in sarcoidosis. Arch Intern Med 2003; 163: 615-620.

108 Hagaman JT, Kinder BW, Eckman MH. Thiopurine S-methyltranferase testing in idiopathic pulmonary fibrosis: a pharmacogenetic cost-effectiveness analysis. Lung 2010; 188: 125-132.

109 Romagnuolo J, Sadowski DC, Lalor E, et al. Cholestatic hepatocellular injury with azathioprine: a case report and review of the mechanisms of hepatotoxicity. Can J Gastroenterol 1998; 12: 479-483.

110 Osiri M, Shea B, Robinson V, et al. Leflunomide for treating rheumatoid arthritis. Cochrane Database Syst Rev 2003; CD002047.

111 Kremer JM, Genovese MC, Cannon GW, et al. Concomitant leflunomide therapy in patients with active rheumatoid arthritis despite stable doses of methotrexate. A randomized, doubleblind, placebo-controlled trial. Ann Intern Med 2002; 137: 726-733.

112 Jenks KA, Stamp LK, O'Donnell JL, et al. Leflunomide-associated infections in rheumatoid arthritis. I Rheumatol 2007; 34: 2201-2203.

113 Martin K, Bentaberry F, Dumoulin C, et al. Neuropathy associated with leflunomide: a case series. Ann Rheum Dis 2005; 64: 649-650.

114 Savage RL, Highton J, Boyd IW, et al. Pneumonitis associated with leflunomide: a profile of New Zealand and Australian reports. Intern Med J 2006; 36: 162-169.

115 Cannon GW, Holden WL, Juhaeri J, et al. Adverse events with disease modifying antirheumatic drugs (DMARD): a cohort study of leflunomide compared with other DMARD. J Rheumatol 2004; 31: 1906-1911.

116 Sawada $\mathrm{T}$, Inokuma $\mathrm{S}$, Sato $\mathrm{T}$, et al. Leflunomide-induced interstitial lung disease: prevalence and risk factors in Japanese patients with rheumatoid arthritis. Rheumatology (Oxford) 2009; 48: 1069-1072.

117 Sato T, Inokuma S, Sagawa A, et al. Factors associated with fatal outcome of leflunomide-induced lung injury in Japanese patients with rheumatoid arthritis. Rheumatology (Oxford) 2009; 48: 1265-1268.

118 Ziegenhagen MW, Rothe ME, Zissel G, et al. Exagerated TNFalpha release of alveolar macrophages in corticosteroid resistent sarcoidosis. Sarcoidosis Vasc Diffuse Lung Dis 2002; 19: 185-190.

119 Baughman RP, Lower EE, Drent M. Inhibitors of tumor necrosis factor (TNF) in sarcoidosis: who, what, and how to use them. Sarcoidosis Vasc Diffuse Lung Dis 2008; 25: 76-89.

120 Baughman RP, Lower EE. Infliximab for refractory sarcoidosis. Sarcoidosis Vasc Diffuse Lung Dis 2001; 18: 70-74.

121 Doty JD, Mazur JE, Judson MA. Treatment of sarcoidosis with infliximab. Chest 2005; 127: 1064-1071. 
122 Saleh S, Ghodsian S, Yakimova V, et al. Effectiveness of infliximab in treating selected patients with sarcoidosis. Respir Med 2006; 100: 2053-2059.

123 Baughman RP. Tumor necrosis factor inhibition in treating sarcoidosis: the American experience. Revista Portuguesa de Pneumonologia 2007; 13: S47-S50.

124 Sandborn WJ, Hanauer SB, Rutgeerts $\mathrm{P}$, et al. Adalimumab for maintenance treatment of Crohn's disease: results of the CLASSIC II trial. Gut 2007; 56: 1232-1239.

125 Sandborn WJ, Rutgeerts P, Enns R, et al. Adalimumab induction therapy for Crohn disease previously treated with infliximab: a randomized trial. Ann Intern Med 2007; 146: 829-838.

126 Schoels M, Aletaha D, Smolen JS, et al. Comparative effectiveness and safety of biological treatment options after tumour necrosis factor $\alpha$ inhibitor failure in rheumatoid arthritis: systematic review and indirect pairwise meta-analysis. Ann Rheum Dis 2012; 71: 1303-1308.

127 Khanna D, Liebling MR, Louie JS. Etanercept ameliorates sarcoidosis arthritis and skin disease. J Rheumatol 2003; 30: 1864-1867.

128 Baughman RP, Lower EE, Bradley DA, et al. Etanercept for refractory ocular sarcoidosis: results of a double-blind randomized trial. Chest 2005; 128: 1062-1067.

129 Sandborn WJ, Hanauer SB, Katz S, et al. Etanercept for active Crohn's disease: a randomized, double-blind, placebo-controlled trial. Gastroenterology 2001; 121: 1088-1094.

130 Wiens A, Venson R, Correr CJ, et al. Meta-analysis of the efficacy and safety of adalimumab, etanercept, and infliximab for the treatment of rheumatoid arthritis. Pharmacotherapy 2010; 30: 339-353.

131 Ramos-Casals M, Brito-Zerón P, Muñoz S, et al. Autoimmune diseases induced by TNF-targeted therapies: analysis of 233 cases. Medicine (Baltimore) 2007; 86: 242-251.

132 Keane J, Gershon S, Wise RP, et al. Tuberculosis associated with infliximab, a tumor necrosis factor-alpha neutralizing agent. N Engl J Med 2001; 345: 1098-1104

133 Dixon WG, Hyrich KL, Watson KD, et al. Drug-specific risk of tuberculosis in patients with rheumatoid arthritis treated with anti-TNF therapy: Results from the British Society for Rheumatology Biologics Register (BSRBR). Ann Rheum Dis 2010; 69: 522-528.

134 Gómez-Reino JJ, Carmona L, Angel Descalzo M, et al. Risk of tuberculosis in patients treated with tumor necrosis factor antagonists due to incomplete prevention of reactivation of latent infection. Arthritis Rheum 2007; 57: 756-761.

135 Matulis G, Jüni $P$, Villiger $P M$, et al. Detection of latent tuberculosis in immunosuppressed patients with autoimmune diseases: performance of a Mycobacterium tuberculosis antigen specific interferon gamma assay. Ann Rheum Dis 2008; 67: 84-90.

136 Furst DE. The risk of infections with biologic therapies for rheumatoid arthritis. Semin Arthritis Rheum 2010; 39: 327-346.

137 Chung ES, Packer M, Lo KH, et al. Randomized, double-blind, placebo-controlled, pilot trial of infliximab, a chimeric monoclonal antibody to tumor necrosis factor-alpha, in patients with moderate-to-severe heart failure: results of the anti-TNF Therapy Against Congestive Heart Failure (ATTACH) trial. Circulation 2003; 107: 3133-3140

138 Felekis T, Katsanos K, Christodoulou D, et al. Reversible bilateral optic neuritis after infliximab discontinuation in a patient with Crohn's disease. J Crohns Colitis 2009; 3: 212-214.

139 Caspersen S, Elkjaer M, Riis L, et al. Infliximab for inflammatory bowel disease in Denmark 1999-2005: clinical outcome and follow-up evaluation of malignancy and mortality. Clin Gastroenterol Hepatol 2008; 6: 1212-1217.

140 Wong AK, Kerkoutian S, Said J, et al. Risk of lymphoma in patients receiving antitumor necrosis factor therapy: a meta-analysis of published randomized controlled studies. Clin Rheumatol 2012; 31: 631-636.
141 Vermeire S, Noman M, Van Assche G, et al. Effectiveness of concomitant immunosuppressive therapy in suppressing the formation of antibodies to infliximab in Crohn's disease. Gut 2007; 56: 1226-1231.

142 Thai A, Prindiville T. Hepatosplenic T-cell lymphoma and inflammatory bowel disease. J Crohns Colitis 2010; 4: 511-522.

143 Kudrin A, Chilvers ER, Ginawi A, et al. Sarcoid-like granulomatous disease following etanercept treatment for RA. I Rheumatol 2007; 34: 648-649.

144 Verschueren K, Van Essche E, Verschueren P, et al. Development of sarcoidosis in etanercept-treated rheumatoid arthritis patients. Clin Rheumatol 2007; 26: 1969-1971.

145 Almodóvar R, Izquierdo $M$, Zarco $P$, et al. Pulmonary sarcoidosis in a patient with ankylosing spondylitis treated with infliximab. Clin Exp Rheumatol 2007; 25: 99-101.

146 Daïen CI, Monnier A, Claudepierre P, et al. Sarcoid-like granulomatosis in patients treated with tumor necrosis factor blockers: 10 cases. Rheumatology (Oxford) 2009; 48: 883-886.

147 Baughman RP, Judson MA, Ingledue R, et al. Efficacy and safety of apremilast in chronic cutaneous sarcoidosis. Arch Dermatol 2012; 148: 262-264

148 Carlesimo M, Giustini S, Rossi A, et al. Treatment of cutaneous and pulmonary sarcoidosis with thalidomide. I Am Acad Dermatol 1995; 32: 866-869.

149 Baz R, Li L, Kottke-Marchant K, et al. The role of aspirin in the prevention of thrombotic complications of thalidomide and anthracycline-based chemotherapy for multiple myeloma. Mayo Clin Proc 2005; 80: 1568-1574.

150 Siltzbach LE, Teirstein AS. Chloroquine therapy in 43 patients with intrathoracic and cutaneous sarcoidosis. Acta Med Scand Suppl 1964; 425: 302-308.

151 Chloroquine in the treatment of sarcoidosis. A report from the research committee of the British Tuberculosis Association. Tubercle 1967; 48: 257-272.

152 Leecharoen S, Wangkaew S, Louthrenoo W. Ocular side effects of chloroquine in patients with rheumatoid arthritis, systemic lupus erythematosus and scleroderma. J Med Assoc Thai 2007; 90: $52-58$.

153 Jones SK. Ocular toxicity and hydroxychloroquine: guidelines for screening. Br J Dermatol 1999; 140: 3-7.

154 Yam JC, Kwok AK. Ocular toxicity of hydroxychloroquine. Hong Kong Med J 2006; 12: 294-304.

155 Munster T, Gibbs JP, Shen D, et al. Hydroxychloroquine concentration-response relationships in patients with rheumatoid arthritis. Arthritis Rheum 2002; 46: 1460-1469.

156 Rebuck AS, Stiller CR, Braude AC, et al. Cyclosporin for pulmonary sarcoidosis. Lancet 1984; 1: 1174.

157 Bomprezzi R, Pati S, Chansakul C, et al. A case of neurosarcoidosis successfully treated with rituximab. Neurology 2010; 75: 568-570.

158 Belkhou A, Younsi R, El Bouchti I, et al. Rituximab as a treatment alternative in sarcoidosis. Joint Bone Spine 2008; 75: 511-512.

159 Gottenberg JE, Guillevin L, Lambotte O, et al. Tolerance and short term efficacy of rituximab in 43 patients with systemic autoimmune diseases. Ann Rheum Dis 2005; 64: 913-920.

160 Lower EE, Baughman RP, Kaufman AH. Rituximab for refractory granulomatous eye disease. Clin Ophthalmol 2012; 6: 1613-1618.

161 Aksoy S, Dizdar O, Hayran M, et al. Infectious complications of rituximab in patients with lymphoma during maintenance therapy: a systematic review and meta-analysis. Leuk Lymphoma 2009; 50: 357-365.

162 Aksoy S, Harputluoglu H, Kilickap S, et al. Rituximab-related viral infections in lymphoma patients. Leuk Lymphoma 2007; 48: 1307-1312.

163 Carson KR, Focosi D, Major EO, et al. Monoclonal antibodyassociated progressive multifocal leucoencephalopathy in patients 
treated with rituximab, natalizumab, and efalizumab: a review from the Research on Adverse Drug Events and Reports (RADAR) Project. Lancet Oncol 2009; 10: 816-824.

164 Kimball AB, Gordon KB, Fakharzadeh S, et al. Long-term efficacy of ustekinumab in patients with moderate-to-severe psoriasis: results from the PHOENIX 1 trial through up to 3 years. $\mathrm{Br} J$ Dermatol 2012; 166: 861-872.

165 Moller DR, Forman JD, Liu MC, et al. Enhanced expression of IL12 associated with Th 1 cytokine profiles in active pulmonary sarcoidosis. J Immunol 1996; 156: 4952-4960. 